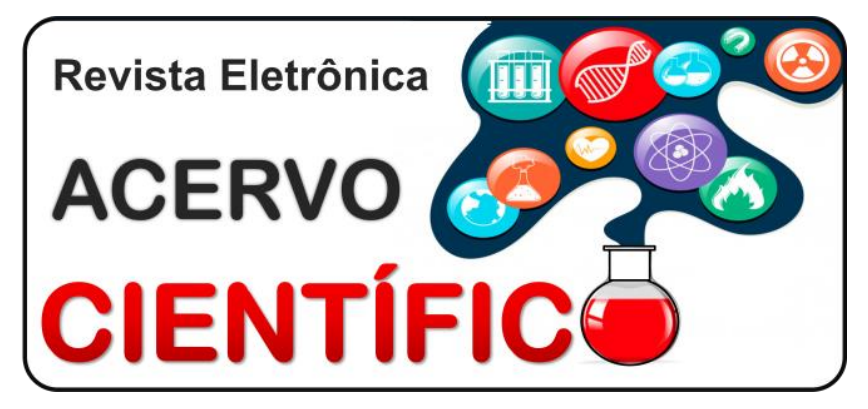

REVISÃO BIBLIOGRÁFICA

Recebido em: 9/2019

Aceito em: 10/2019

Publicado em: 10/2019

\title{
Intervenção do enfermeiro frente ao tratamento de úlcera venosa: revisão bibliográfica
}

\author{
Intervention of the nurse regarding the treatment of venous ulcer: bibliographic review \\ Intervención de la enfermera en relación con el tratamiento de la úlcera venosa: revisión \\ bibliográfica
}

Aline Rieger Reis Cesar ${ }^{1 *}$.

\begin{abstract}
Resumo: Este artigo pretende apresentar a intervenção prestada pelo enfermeiro ao paciente portador de úlcera venosa de membros inferiores com o foco de atenção não só voltado principalmente a abordagens curativas e centradas na técnica. A insuficiência venosa crônica é a causa principal da úlcera venosa, causando uma obstrução parcial ou total de vasos dos Membros Inferiores (MMII). Essas úlceras comumente causam edema, dor local, podendo apresentar exsudato e odor fétido, sendo maléolo medial e do terço distal da perna a localização mais frequente. Os resultados apontam quanto a necessidade de atualização técnico e científico constante para a melhor intervenção quanto ao tipo do tratamento e orientações para prevenção de feridas exige, sendo condição imprescindível o envolvimento de toda a equipe multiprofissional.
\end{abstract}

Palavras-chave: Enfermagem, Assistência, Úlcera venosa.

\begin{abstract}
This article intends to present the intervention provided by the nurse to the patient with venous ulcer of lower limbs with the focus of attention not only focused mainly on curative and technique-centered approaches. Chronic venous insufficiency is the main cause of venous ulcer, causing a partial or total obstruction of vessels of the Lower Limbs (II). These ulcers commonly cause edema, local pain, and may present exudate and foul odor, being medial malleolus and distal third of the leg the most common location . The results indicate that the need for constant technical and scientific updating for the best intervention regarding the type of treatment and guidelines for the prevention of wounds requires, being an indispensable condition the involvement of the entire multiprofessional team.
\end{abstract}

Keywords: Nursing, Assistance, Venous ulcer.

Resumen: Este artículo pretende discutir de la estrategia de defensa de la marca y su reputación de la imagen de la institución corporativa ante los ataques y críticas a la calidad de sus productos y servicios exponiendo inevitablemente de forma positiva o negativamente sus marcas en las redes sociales. El trabajo evalúa la interacción de las organizaciones junto a los usuarios con el objetivo de cumplir la misión de defender su marca ante los juicios que puedan exponer de forma negativa los productos y servicios de la marca que a lo largo de los años lucha para sobrevivir a las actuales situaciones económicas del país

Palabras clave: Enfermería, Asistencia, Úlcera venosa.

${ }^{1}$ Centro Universitário Plínio Leite (Universidade Anhanguera). Niterói, RJ. *E-mail: alinerieger@uol.com.br 


\section{INTRODUÇÃO}

A insuficiência venosa é descrita por Aguiar ET et al (2005), como resultado da obstrução das válvulas venosas nas pernas ou de um fluxo de sangue para trás através das válvulas, afetando as veias superficiais e profundas. Esse distúrbio no mecanismo fisiológico do fluxo venoso resulta de acordo com Borges EL (2001) em hipertensão venosa, em virtude do aumento prolongado da pressão nos vasos. As paredes das veias são mais delgadas e complacentes que as paredes das artérias, acabam por se distender prontamente quando a pressão venosa se eleva de maneira consistente. Assim, os folhetos das válvulas venosas são estirados e impedidos de se fechar por completo, permitindo um refluxo retrógrado do sangue. Souza AC et al (2005) defende que a cicatrização das feridas leva muito tempo, ou mesmo anos, para efetivar-se e, caso não sejam adotadas medidas preventivas, há um índice de até $70 \%$ de recidivas.

Silveira LMC E Ribeiro VMB (2004) descreve fatores importantes que influenciam nessa cicatrização e na cronicidade das feridas, incluindo problemas como diabetes, hipertensão, anemia, falta de exercícios físicos regulares, estado nutricional e repouso deficitário.

Silva FAA et al (2009) argumenta que é fundamental que o enfermeiro, seja hábil para planejar, avaliar e executar a assistência de enfermagem ao paciente portador de feridas tendo por base todos os seus conhecimentos técnicos e científicos. A relevância do tema refere-se ao grande e crescente número de pacientes acometidos da ocorrência dessa afeç̧ão.

Aguiar ET et al (2005) defende que no Brasil estima-se que aproximadamente $3 \%$ da população é portadora desse tipo de lesão, no caso dos diabéticos esse número se eleva para $10 \%$. O mesmo autor afirma que cerca de 4 milhões de pessoas são portadoras de lesões crônicas ou possuem algum tipo de complicação no processo de cicatrização, o que requer além do conhecimento dos profissionais um investimento em pesquisas e busca de novos recursos e tecnologias.

É fundamental que o enfermeiro, seja capaz de planejar, avaliar e executar a assistência de enfermagem ao paciente portador de feridas tendo por base todos os seus conhecimentos técnicos e científicos. Silva FAA et al (2009) argumenta que várias complicações são decorrentes da úlcera venosa como repercussões físicas, sociais, econômicas e emocionais que podem interferir na qualidade de vida dos portadores desse tipo de lesão. Dessa forma, o mesmo autor defende que, torna-se necessário a sistematização do cuidado com esses pacientes, constituindo a avaliação da ferida fator determinante para a implantação de uma terapêutica adequada.

O objetivo deste trabalho consiste em identificar através de uma pesquisa bibliográfica, desenvolvida com base em material já elaborado, principalmente em livros e artigos científicos existentes demonstrar como deve ser a intervenção prestada pelo enfermeiro ao paciente portador de úlcera venosa de membros inferiores com o foco de atenção.

\section{REVISÃO BIBLIOGRÁFICA}

\section{Conceito e incidência da úlcera venosa}

A úlcera venosa ou úlcera de perna é caracterizada de acordo com Carpenito LJ (1999) por um conjunto de fatores que favorecem o aniquilamento ao redor ou irregular da topografia da derme ou epiderme, atingindo subcutâneo e tecidos subjacentes, acometendo as extremidades dos membros inferiores e de etiologia, geralmente, interligada ao sistema vascular arterial ou venoso.

Autores como Silveira LMC e Ribeiro VMB et al (2004) acrescentam que as úlceras venosas são feridas crônicas e que se relacionam com a hipertensão venosa dos membros inferiores (MMII) sendo que de 80 a $90 \%$ das úlceras localizam nesses membros, causando problema se saúde pública grave, respondendo por considerável impacto socioeconômico financeira e inviabilizando atividade laboral.

As úlceras venosas são definidas conforme Carpenito LJ (1999) por lesão da pele localizada em torno do tornozelo ou parte inferior da perna em sua grande maioria e causadas pela hipertensão venosa prolongada. A insuficiência venosa crônica também conhecida como síndrome pós flebítica refere-se à 
sequência de eventos antecedendo as úlceras de estase venosa crônica destruindo as válvulas das veias da perna o que as tornam incompetentes.

Autores como Carmo SS, et al (2007) em um levantamento quanto a prevalência e incidência de úlceras de perna que foi realizado no estado de São Paulo (município de Botucatu) a prevalência foi de aproximadamente $1,5 \%$ de casos de úlceras venosas ativas ou cicatrizadas.

Na prática dos serviços de saúde, Abbade LPF e Lastoria S (2006) observaram que o portador de úlcera venosa é atendido com frequência para consultas médicas, trocas de curativos com sucessivas mudanças do tratamento tópico e, às vezes, sem a associação de qualquer terapia de compressão, podendo este paciente conviver durante vários anos com essa situação desgastante, sem obter a cicatrização da úlcera.

\section{Etiopatogenia e fisiopatologia}

Borges EL et al (2007) descreve a etiologia da úlcera de estase como a insuficiência venosa crônica provocada principalmente por incompetência do sistema venoso superficial associado ou não à incompetência do sistema venoso profundo, com insuficiência valvular e/ou obstrução venosa. Autores como Aguiar ET al (2005) enfatiza a importância dos critérios levantar as hipóteses da etiologia das úlceras venosa: Presença de varizes essenciais ou secundárias; inventário familiar; incompetência valvular venosa profunda; Síndrome pós-trombótica; constrição venosas extrínsecas; história de oclusões venosas por trombose e flebite. Segundo o autor, as hipóteses levantadas podem estar na etiologia dos fenômenos que resultam na hipertensão venosa e que respondem pela insuficiência venosa crônica e ulceração venosa.

Duas teorias são descritas por Carmo SS et al (2007) explicitando a fisiopatologia da úlcera venosa. A extensão do leito capilar é devido ao aumento da pressão venosa, o que ocasiona alteração no diâmetro dos poros intersticiais e extravasamento de fibrinogênio, responsável pelo acúmulo de fibrina. Esse armazenamento de fibrina interfere na difusão de oxigênio e nutrientes, predispõe à formação de úlceras ao formar manguitos. A segunda hipótese seria que os leucócitos ao serem expostos à pressão venosa elevada são subtraídos na parede endotelial no leito capilar, estes, em contato com moléculas de adesão intracelulares na parede capilar, as células que produzem a liberação de citoquinas e radicais livres no leito venoso ativam, ocasionando reação inflamatória, lesionando as válvulas venosas e tecido adjacente, o que predispõe a formação da lesão venosa.

Embora não há conhecimento exato quanto a etiologia, Morais GFC et al (2008) descreve que na literatura há concordância que a hipertensão venosa é causa principal para as feridas dos MMII, justificando pelo fato do sistema venoso funcionar como reservatório sanguíneo e com o encargo de realizar a pequena circulação (carrear o sangue desoxigenado de volta ao coração). Por sua vez, as veias da panturrilha, com os tecidos circundantes, agem como coração periférico, drenando sangue venoso durante o exercício. Esse fluxo de sangue sob condições normais ocorre por três sistemas de veias unidirecionalmente: o superficial, o profundo e o perfurante com diferenças anatômicas. A ligação entre os sistemas superficial e o profundo ficam a cargo das veias do sistema perfurante, com refluxo do mesmo durante o relaxamento da musculatura das pernas sendo bloqueado (MORAIS GFC, et al,2008)

A musculatura da panturrilha, atua como bomba periférica, com o cargo de auxiliar as válvulas a superar a força da gravidade, diminuindo dessa forma, a pressão no interior das veias ao direcionar o sangue para o coração. A pressão venosa é o resultado da pressão hidrostática que a coluna de sangue exerce entre as pernas e o átrio direito. Essa pressão nas veias profundas chega a quase $0 \mathrm{mmHg}$ em posição supina, aumentando em pé, aproximando de $80 \mathrm{mmHg}$ a $90 \mathrm{mmHg}$. Na deambulação, ocorre contração muscular, sobre as veias profundas, desse modo, a pressão venosa decai para $30 \mathrm{mmHg}$ em um estado que intitulamos fisiológico (MORAIS GFC, et al, 2008). Quando ocorre imperfeição nesse mecanismo fisiológico ocasionado pela hipertensão venosa em deambulação, resulta em edema, lipodermatosclerose e ulceração, que é decorrente do acúmulo excessivo de líquido e de fibrinogênio no tecido subcutâneo. Este processo ocorre devido ao fato da função fisiológica que é dependente da integridade anatômica das veias, da competência do sistema valvular e do bom funcionamento da bomba periférica (GAMBA MA ,1994). 
Não há estudos robustos que fazem relação à formação de úlceras nos membros inferiores com a pressão elevada. Alguns estudiosos como Pereira Al e Bachion MM (2005), levantam a hipótese que a hipertensão venosa crônica poderia ocasionar essas alterações vasculares. A incompetência das veias perfurantes da região do tornozelo é agente principal para a hipertensão venosa, pois, as pressões elevadas no interior dos vasos ao longo da vida, ocasionam deterioração na microcirculação , comprometendo consideravelmente as paredes dos vasos, desencadeando alterações cutâneas sob a forma de edema, eczema, mudança na coloração decorrente da hiperpigmentação, endurecimento da pele envolvendo as panturrilhas e desse modo culminando na ulceração do tecido, causado pelo aumento da permeabilidade capilar e liberação de macromoléculas do seu interior para a pele.

O destaque que muitos autores fazem em relação aos processos envolvidos na formação da úlcera venosa, entre eles, Silva JLA e Lopes MJM (2006) é que todas as hipóteses teóricas descritas não são excludentes e, possivelmente, todas possam estar envolvidas no mecanismo da patogênese da úlcera venosa, defendem que não existe consenso literário.

\section{Diagnóstico clínico diferencial}

A condição obrigatória antes de iniciar o tratamento de uma úlcera de perna consiste em fazer uma avaliação detalhada buscando reconhecer a sua origem. Se o diagnóstico inicial for equivocado, leva a condutas inadequadas, principalmente relacionadas às terapias por compressão que são primordiais no tratamento das úlceras venosas. Existem características inerentes que viabilizam a realização do diagnóstico diferencial das úlceras venosas, em contraponto às feridas provocadas por deficiência de circulação arterial ou por comprometimento neurológico (SILVA JLA e LOPES MJM, 2006).

Abbade LPF e Lastoria S (2006) caracterizam úlcera venosa como lesão de borda irregular, inicialmente superficial, mas podendo se tornar profunda, com bordas bem definidas e em geral exsudativas de coloração amarelada, sendo pouco frequente presença de tecido necrótico e exposição de tendões. A dor é sintoma relatado frequentemente pelos pacientes e de intensidade variável e independente do tamanho da úlcera, apresentando piora ao final do dia com a posição ortostática e ocorrendo melhora após elevação do membro. Pode ocorrer também eczema que é caracterizado por eritema, descamação, prurido e eventualmente exsudato. Outra característica diferencial é o endurecimento da derme e tecido subcutâneo ao qual é definido por lipodermatoesclerose que por causar um aumento na produção de melanina, ocasiona a hiperpigmentação da pele caracterizando por um escurecimento da pele devido ao extravazamento dos glóbulos vermelhos rompidos decorrente da liberação de hemoglobina, outra característica diferencial devido a congestão do fluxo sanguíneo refere-se a presença de veias varicosas.

Dealey C (2001) enfatiza quanto a necessidade de realizar a ultrassonografia Doppler para determinar o índice sistólico entre tornozelo e o braço, índice de pressão tornozelo/braquial (IPTB/ ITB). A investigação para avaliar a circulação arterial é condição primordial para os pacientes com ulcerações de MMII.

A mensuração do Índice de Pressão Tornozelo/Braço (IPTB) é utilizado também para o diagnóstico diferencial, assim como a palpação dos pulsos distais. A divisão da pressão sistólica em artéria do pé pela pressão sistólica do braço resulta-se no IPTB, sendo que o parâmetro de normalidade se encontra próxima de 1,0. É um exame não invasivo, útil para dar suporte no diagnóstico de doenças arteriais dos membros inferiores. O índice é calculado com o valor mais alto da pressão sanguínea sistólica do tornozelo dividido pela pressão sanguínea sistólica da artéria braquial. O IPTB maior ou igual a 0,9 indica suprimento arterial normal para a perna. Quando menor que 0,9 , existe alguma isquemia presente, a terapia compressiva não deve ser usada se o IPTB for menor que 0,8. Havendo dúvidas, deve-se encaminhar o paciente para avaliação médica adicional (DEALEY C, 2001).

\section{Intervenção do enfermeiro e da equipe multiprofissional}

Quando refletimos em relação à assistência aos portadores de uma lesão crônica, é imprescindível atentar na importância do diagnóstico diferencial, sua evolução, a terapêutica indicada, haja vista que, são refratárias a diversos tipos de tratamentos, pois são decorrentes de situações que inviabilizam a cicatrização normal (DEALEY 2001). 
Abbade LPF e Lastoria S (2006) corroboram que por ser uma operação dinâmica, complexa e que requer uma atenção especial é imprescindível estar atento as peculiaridades de cada paciente.

A implementação da sistematização da assistência por meio do processo de enfermagem implementado ao portador de lesões crônicas é defendida por Carmo SS et al (2007) que a equipe multidisciplinar é indispensável para o sucesso do tratamento, tornando-se primordial, em virtude do desfecho positivo encontrado no tratamento de feridas, através dos esforços somados entre todos os membros da equipe, com objetivo de sanar a doença, e visualizar o cliente de forma holística, humanizada e individualizada, aliando-se a todos os conhecimentos específicos.

Silva FAA (2009) defende a relevante atuação do enfermeiro exercida na assistência ao paciente portador de úlceras de MMII, como o profissional primordial para avaliar o cuidado prestado diariamente, além de possuir conhecimento técnico, ético e científicos que são indispensáveis à prática do profissional.

O processo de enfermagem por meio de avaliações de sistematizadas, prescrições de enfermagem individualizadas e reavaliadas rotineiramente de acordo com o momento evolutivo do processo cicatricial sendo este processo dinâmico e fundamental para o acompanhamento adequado. É importante respeitar todas as peculiaridades de cada paciente, recursos materiais e humanos disponíveis para o tratamento e factibilidade do paciente continuar o tratamento após a alta. A escolha das coberturas deve se levar em conta alguns fatores como as indicações, às contra indicações, aos custos e à eficácia, e a factibilidade financeira do paciente arcar com o custo do tratamento após a alta. (DEALEY 2001)

Visando a boa prática assistencial, devermos considerar seis pilares de acordo com Silveira LMC e Ribeiro VMB et al (2004): repouso, terapia compressiva; terapia tópica (com escolha de coberturas locais que mantenha úmido e limpo o leito da ferida com capacidade de absorver o exsudato); tratamento da estase venosa, antibioticoterapia sistêmica objetivando o controle da infecção e prevenção de recidivas.

Borges EL et al. (2007) elucida que para uma assistência eficaz é necessário questionar ao paciente se há episódios de dor (em caso positivo, avaliar a intensidade), avaliar presença de edema, presença ou ausência de pulso, mensurar extensão e profundidade da ferida, peculiaridades da pele e de suas bordas, se há exsudato (observando quantidade, odor e coloração) e sinais de infecção.

Outros quesitos referem-se a avaliação das características da úlcera e a definição da terapêutica eficaz sendo importante para a escolha da cobertura apropriada a ser utilizada, levando em conta, que o profissional deve avaliar com muita cautela se a úlcera de MMII requer desbridamento, se há presença de infecção, secreção, cavidade a ser preenchida e exposição óssea. Estas características deverão ser avaliadas cuidadosamente, levando em conta que o leito da lesão deverá basear-se em condições ideais para a cicatrização, ou seja, com umidade para que haja integridade de suas funções (BORGES EL, 2001).

Autores como Morais GFC et al., (2008) corroboram quanto a necessidade da interconsulta médica para avaliar a necessidade de intervenções cirúrgicas e uso de terapêutica de compressão do membro afetado, assim como tratamento tópico com produtos de ação cicatrizante e bactericidas associados à orientação ao paciente para necessidade de manutenção do repouso prolongado.

Abbade LPF e Lastoria S., (2006) destacam a terapêutica da compressão por bandagem compreendendo em três etapas: estiramento curto, estiramento longo e uso de meias compressivas elásticas. A indicação para a terapêutica da bandagem de curto estiramento é quando existe presença de edema , apresentando contra indicação em pacientes que não deambulam, já que esta bandagem produz quase e/ou nenhum efeito na elasticidade sendo que o efeito para ser alcançado deve-se pela contração e relaxamento do músculo da panturrilha; A que possui uma grande benefício, pelo fato da manutenção da compressão ocorrer por vários dias mesmo quando o membro fica elevado, refere-se bandagem de longo estiramento, sendo eventualmente utilizada devido ao alto custo financeiro; e as meias elásticas de compressão que estabelece uma compressão média a alta, sendo uma alternativa com custo mais reduzido, propiciando o autocuidado, além de não produz odores desagradáveis considerando o uso adequado, com a orientação de serem substituídas a cada seis meses. 
É importante frisar que a investigação das características diferenciais inerentes à úlcera de MMII como, característica e volume da secreção exsudativa, odor, presença de fibrina, esfacelo, grau de granulosidade serão fatores primordiais para escolha da cobertura ideal visando auxiliar no processo reparação tecidual além da compressão que deverá estar incluída nesta terapêutica (ABBADE LPF e LASTORIA S, 2006).

Silva JLA e Lopes MJM (2006) acrescentam que é importante agregar ações na terapêutica que propiciem o retorno venoso adequado, favorecem uma cicatrização mais rápida dessas lesões se ocorrer redução no edema, o que beneficia um tratamento eficaz aliado à terapia compressiva, repouso, exercícios e deambulação.

Dealey C (2001) corrobora que o maior desafio para o enfermeiro que assiste estes pacientes é propiciar um ambiente fisiológico à ferida favorecendo a cicatrização e evitando desidratação e/ou morte celular.

\section{CONSIDERAÇÕES FINAIS}

Após a análise dos artigos e da literatura especializada, o tratamento adequado e eficaz das úlceras venosas é um desafio a ser enfrentado pelos profissionais de saúde que se dedicam a esta área. Os trabalhos revisados neste estudo apontaram divergências e questionamentos no que se refere ao tratamento, embora condutas foram sugeridas para um direcionamento efetivo. Os resultados refletem a importância de cursos de especialização voltados para tratamento de feridas buscando alcançar conhecimento e habilidade para prestar assistência de qualidade e diferenciada aos portadores de úlceras venosas, assim como para que todos os cuidados sejam prestados de forma adequada, além da participação do paciente portador de úlcera no processo de cicatrização e controle de recidivas, o profissional deve ter uma educação apropriada, treinamento, habilidades e competências, todas essas diretrizes devem ser aplicadas a realidade vivenciada tanto pelo profissional quanto pelo paciente.

\section{REFERÊNCIAS}

1- ABBADE LPF, LASTORIA S. Abordagem de pacientes com úlcera da perna de etiologia venosa. Anais Brasileiro Dermatologia. 2006; 81(6):509-22.

2- AGUIAR ET, PINTO LJ, FIGUEIREDO MA et al Diretrizes sobre diagnóstico, prevenção e tratamento da Sociedade Brasileira de Angiologia e Cirurgia Vascular (SBACV): Úlcera de insuficiência venosa. J. Vasc. Bras 2005; 4(supl.2): 195200.

3- BORGES EL. Feridas :Limpeza e Desbridamento.. Belo Horizonte. Coopmed, 2001. p.77-95.

4- BORGES EL, et al. Revisão sistemática do tratamento tópico da úlcera venosa. Rev. Latino-Am. Enfermagem [online]. 2007, vol.15, n.6, pp. 1163-1170.

5- CARMO SS, CASTRO CD, RIOS VS et al. Atualidades na assistência de enfermagem a portadores de úlcera venosa. Rev. Eletr. Enf. [Internet]. 2007; 9(2): 506-17.

6- CARPENITO LJ. Planos de cuidados de enfermagem e documentação: diagnósticos de enfermagem e problemas. 2. ed. Porto Alegre: Artmed, 1999. p 30-53

7- CERVO AL, BERVIAN PA. Metodologia científica. 5a. ed. São Paulo: Pearson Prentice Hall; 2005.

8- DEALEY C. Cuidado de Feridas: um guia para as enfermeiras. São Paulo: Atheneu, 2001. p.2-137

9- GAMBA MA. A importância da assistência de enfermagem na prevenção, controle e avaliação à pacientes portadores de diabetes com neuropatia e vasculopatia. Acta Paul Enf, São Paulo, v. 4, n. 2/4, 1991, p. 7-19.

10- MORAIS GFC, et al. Avaliação de feridas pelos enfermeiros de instituições hospitalares da rede pública. Texto contexto enfermagem, São Paulo, v.17, n.1, jan./mar. 2008 p. 98-105.

11- PARTSCH H. Classificação da Insuficiência Venosa Crônica - CEAP. In: Thomaz J B, Belczak C E Q. Tratado de Flebologia e Linfologia. Rio de Janeiro: Rubio; 2006. p 85-89.

12- PEREIRA AL, BACHION MM. Tratamento de feridas: análise da produção científica publicada na Revista Brasileira de Enfermagem de 1970-2003. Revista brasileira enfermagem, São Paulo, v.58, n.2, p. 208-213, mar./abr. 2005.

13- POLIT DF, BECK CT, HUNGLER BP. Fundamentos de pesquisa em enfermagem: métodos, avaliação e utilização. 5a. ed. Porto Alegre: Artmed; 2004

14- SILVA JLA, LOPES MJM. Educação em saúde a portadores de úlcera varicosa através de atividades de grupo. Rev Gaúcha Enferm, Porto Alegre (RS) 2006 jun;27(2):240-50.

15- SILVA FAA, et al. Enfermagem em estomaterapia: cuidados clínicos ao portador de úlcera venosa. Rev. bras. enferm. [online]. 2009, vol.62, n.6, pp. 889-893.

16- SILVEIRA LMC, RIBEIRO VMB. Grupo de adesão ao tratamento: espaço de "ensinagem" para profissionais de saúde e pacientes. Interface: Comunicação, Saúde, Educação, Botucatu (SP) 2004 set;9(16):91-104.

17- SOUZA AC, et al. A educação em saúde com grupos na comunidade: uma estratégia facilitadora da promoção da saúde. Revista Gaúcha de Enfermagem, Porto Alegre (RS) 2005 ago; 26(2): 147-53. 